\title{
ОРГАНИЗАЦИОННО-ЭКОНОМИЧЕСКИЕ ИНСТРУМЕНТЫ ОПТИМИЗАЦИИ СТРАТЕГИЧЕСКОГО ПЛАНИРОВАНИЯ НА МИКРОЭКОНОМИЧЕСКОМ УРОВНЕ
}

\author{
(c) 2021 Янченко Дмитрий Валерьевич \\ кандидат технических наук, доцент, доцент кафедры менеджмента \\ Новочеркасский инженерно-мелиоративный институт им. А. К. Кортунова - \\ филиал Донского государственного аграрного университета, Россия, Новочеркасск \\ E-mail: Yn70@mail.ru
}

\section{(c) 2021 Важинская Любовь Юрьевна}

магистрант

Южно-Российский государственный политехнический университет (НПИ) имени М.И. Платова, Россия, Новочеркасск

E-mail: lyubov20081990@yandex.ru

\section{(c) 2021 Васькина Валентина Николаевна магистрант}

Южно-Российский государственный политехнический университет (НПИ) имени М.И. Платова, Россия, Новочеркасск

E-mail: valentinka_856@mail.ru

\section{(C) 2021 Ковязо Екатерина Альбертовна магистрант}

Южно-Российский государственный политехнический университет (НПИ) имени М.И. Платова, Россия, Новочеркасск

E-mail: kovyaso_ekaterina@mail.ru

В статье исследуется эволюция концептуально-теоретических подходов к стратегическому планированию на микроэкономическом уровне, на примере хозяйствующего субъекта агропромышленного комплекса обоснована стратегия развития на период 2022-2025 гг., предложены организационно-экономические инструменты, направленные на оптимизацию процесса стратегического планирования на корпоративном уровне.

Ключевые слова: микроэкономический уровень, развитие, стратегия, планирование, конкурентоспособность.

Стратегический управленческий учёт (Strategic Management Accounting - SMA), как доктрина максимизации эффективности управленческих процессов на микроэкономическом уровне, сформировался на основе анализа влияния различных факторов внутренней и внешней среды на результаты развития фирмы с помощью методов эконометрического анализа. Важным элементом стратегического управления является стратегическое планирование (стратегирование) на корпоративном уровне, позволяющее усилить конкурентные преимущества хозяйствующего субъекта. Указанные обстоятельства подтверждают актуальность и своевременность настоящей статьи.

В познании содержания стратегического управленческого учёта как информационного ресурса и аналитического инструмента стратегического менеджмента отправной точкой следует считать исследование основных понятий стратегического менеджмента. Рассмотрим эволюцию научных подходов к вопросам стратегического планирование фирмы (таблица $1[1,5,7])$.

Отражённая в таблице 1 эволюция научных подходов к стратегическому планированию показывает, что в обобщённом виде корпоративная стратегия основывается на взаимозависимости, взаимообусловленности и взаимодействии системы «цель - направления (векторы) действий - ресурсы обеспечения». Стратегические цели подразумевают чёткую фиксацию действий экономического агента в отношении 
Таблица 1. Эволюция концептуально-теоретических подходов к стратегическому планированию на микроэкономическом уровне

\begin{tabular}{|c|c|c|}
\hline $\begin{array}{l}\text { Корпоративная стратегия } \\
\text { определяется как: }\end{array}$ & Основоположник подхода & Сущность подхода: \\
\hline $\begin{array}{l}\text { метод определения конкурентных } \\
\text { целей организации }\end{array}$ & $\begin{array}{l}\text { Гарвардская бизнес-школа, } \\
\text { 60-е гг XX века }\end{array}$ & $\begin{array}{l}\text { Обосновываются приоритетные направ- } \\
\text { ления развития бизнеса фирмы на сред- } \\
\text { не- долгосрочный период }\end{array}$ \\
\hline $\begin{array}{l}\text { метод установления долгосрочных } \\
\text { целей организации, её действий по } \\
\text { размещению ресурсов }\end{array}$ & А. Чандлер & $\begin{array}{l}\text { Стабильность сформированных целей } \\
\text { развития, невозможность их пересмотра } \\
\text { вне изменения рыночной конъюнктуры }\end{array}$ \\
\hline $\begin{array}{l}\text { формат реагирования на вновь } \\
\text { возникающие возможности и риски } \\
\text { за счёт активизации внутренних } \\
\text { резервов }\end{array}$ & М. Портер 1980-1985 г.г. & $\begin{array}{l}\text { Обосновывается необходимость форми- } \\
\text { рования конкурентных преимуществ, } \\
\text { действующих в течение длительного } \\
\text { периода }\end{array}$ \\
\hline $\begin{array}{l}\text { метод целеполагания для корпора- } \\
\text { тивного, финансового, производ- } \\
\text { ственного, маркетингового блоков } \\
\text { управления }\end{array}$ & $\begin{array}{l}\text { И. Ансофф, Стейнер, П. Ло- } \\
\text { ранж, и другие исследова- } \\
\text { тели }\end{array}$ & $\begin{array}{l}\text { Основывается на ранжировании целей по } \\
\text { степени важности/срочной реализации } \\
\text { в зависимости от степени из влияния на } \\
\text { результат экономической деятельности }\end{array}$ \\
\hline $\begin{array}{l}\text { взаимосвязанная и взаимообуслов- } \\
\text { ленная система управленческих } \\
\text { решений }\end{array}$ & Г. Мицберг & $\begin{array}{l}\text { Основывается на перманентном контроле } \\
\text { реализации целей, установленных доку- } \\
\text { ментами стратегического планирования } \\
\text { фирмы }\end{array}$ \\
\hline $\begin{array}{l}\text { формат идентификации экономи- } \\
\text { ческих и неэкономических (куль- } \\
\text { турных, социальных, исторических } \\
\text { и др.) факторов, обеспечивающих } \\
\text { конкурентное преимущество фир- } \\
\text { мы }\end{array}$ & Г. Хамель & $\begin{array}{l}\text { Основными факторами стратегического } \\
\text { развития являются корпоративные цен- } \\
\text { ности, миссия, культура. }\end{array}$ \\
\hline $\begin{array}{l}\text { алгоритм операций, направленных } \\
\text { на реализацию установленных } \\
\text { показателей }\end{array}$ & А. Томпсон & $\begin{array}{l}\text { Стратегия является технократическим } \\
\text { инструментом развития хозяйствую- } \\
\text { щего субъекта в течение определённого } \\
\text { периода }\end{array}$ \\
\hline
\end{tabular}

собственного рыночного позиционирования, в частности: какие продукты/услуги производить, по какой цене продавать, кому продавать, какие новые направления деятельности осваивать, на какие ресурсы рассчитывать, что противопоставлять конкурентам. Совокупность составляющих экономической системы фирмы позволяет прогнозировать эффект от реализации мероприятий стратегического планирования в кратко-, средне- и долгосрочной перспективах. Своевременная индикация отклонений от плановых ориентиров позволяет менеджменту корректировать реализацию корпоративной стратегии. В связи со сказанным, грамотное целеполагание корпоративной стратегии развития является одной из важнейших задач управленческой деятельности топ-менеджмента организации.

Для успешной реализации стратегических целей фирма может использовать такие инструменты, как изменение ассортимента выпускаемых товаров/услуг, управление объёмом производства, корректировка цен, и другие функциональные или целевые инструменты (финансовые, маркетинговые и т.д.).
При формировании корпоративной стратегии необходимо учитывать такие факторы, как: уровень платёжеспособного спроса, потребительские предпочтения, технико-технологические инновации, действия конкурентов, кадровый потенциал организации, государственное регулирование, культурные особенности.

Использование инструментов стратегического планирования целесообразно для хозяйствующих субъектов микро-, мезо-, мазоэкономического уровня. Зачастую собственники хозяйствующих субъектов не занимаются оперативным управлением бизнес-процессами. В подобных условиях документы стратегического планирования, с чётко зафиксированными целевыми показателями развития, становятся эффективным инструментом контроля нанятых управленцев и топ-менеджеров.

По мнению некоторых исследователей [2, 4] стратегического менеджмента, корпоративное стратегирование представляет собой набор действий для выработки управленческих решений, которыми организация руководствуется в своей деятельности. Укажем на следующие характери- 
зующие признаки стратегии:

1. Подготовка стратегии развития не оканчивается немедленными действиями по её воплощению на практике. В большинстве случаев заданные стратегические векторы конкретизируются в документах, имеющих подчинённый по отношению к стратегии характер.

2. Подготовленная стратегия развития в целях максимизации эффекта применяется для концентрации ресурсов на наиболее перспективных участках работы (кадры, НИОКР, маркетинг и т.д.).

3. При подготовке стратегии развития организации необходимо стремиться к максимально полному учёту всех возможных вариантов развития событий, возникающих при реализации мероприятий, предусмотренных планами. Во многих случая прогнозирование затруднено недостатком достоверной информации. Фактор неопределённости необходимо учитывать при сценарном прогнозировании на всех этапах и уровнях корпоративного планирования.

С учётом вышеизложенного, стратегия представляет собой выражение намерений собственников/менеджеров хозяйствующего субъекта в отношении производственного, маркетингового и коммерческого потенциала фирмы, способов и критериев распределения инвестиций, доходов, издержек. Вместе с тем, представители научного сообщества [6] указывают на то, что сущность дефиниции стратегия подвергается корректировке с течением времени, так как накапливается опыт реализации различных управленческих практик в условиях меняющейся среды, что оказывает непосредственное влияние на поведение фирмы. Апробируем вышеизложенный инструментарий стратегического корпоративного планирования на примере сельскохозяйственного товаропроизводителя Ростовской области ООО «Аксайская нива» (таблица 2).

В завершение необходимо сформулировать следующие основные выводы.

1. В современных условиях, организация стратегического планирования на мезоэкономическом уровне позволяет хозяйствующему субъекту повысить эффективность системы управления за счёт чёткого целеполагания на долго-, средне- и краткосрочный периоды, оптимального распределения ресурсов и полномочий между структурными подразделениями организации в зависимости от стратегических целей развития, персонификации ответствен-

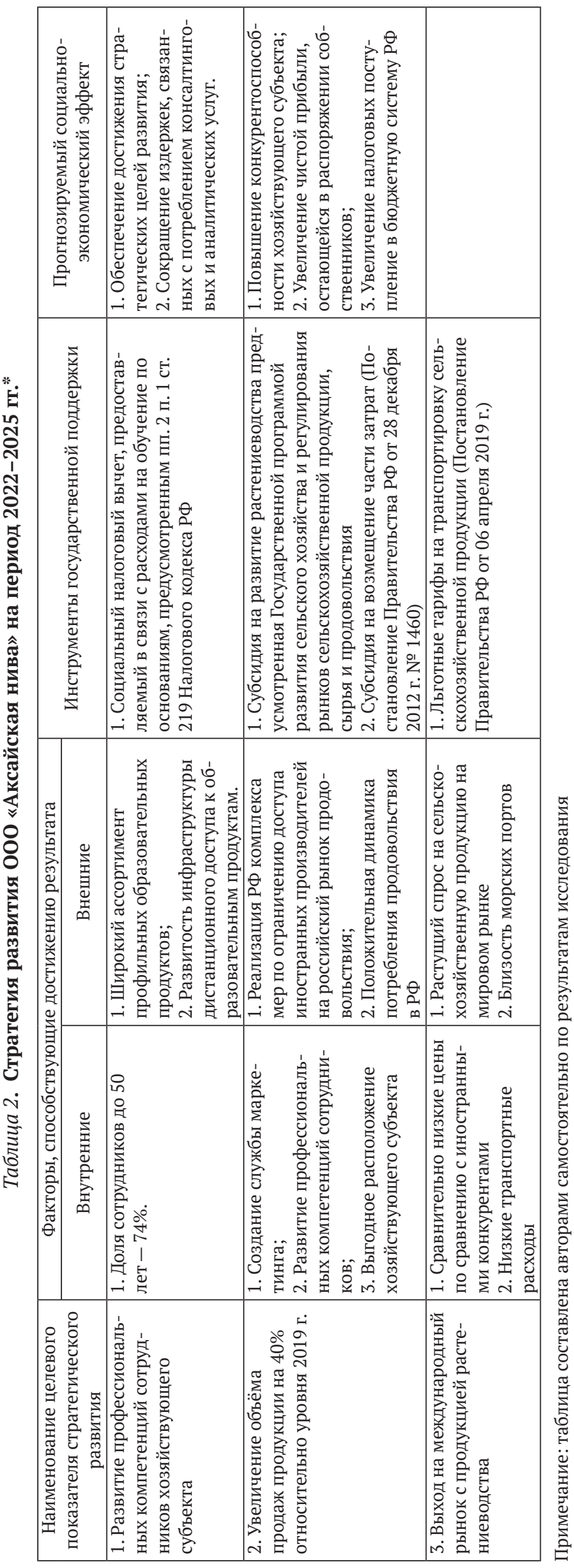


ности за достижение установленных показателей. Совокупное действие вышеизложенных факторов способствует повышению конкурентоспособности как хозяйствующих субъектов, в частности, так и всей экономической системы, в целом.

2. Использование цифровых инструментов в стратегическом планировании на корпоративном уровне позволяет усилить положительное действие упоминавшихся ранее факторов конкурентоспособности. Например, формирование электронных массивов данных (Big-data) о потребителях товаров и услуг, поставщиках и под- рядчиках позволяет упростить реализацию маркетинговых мероприятий, снизить издержки, связанные с администрированием взаимодействия с клиентами, упростить поиск наиболее выгодных контрагентов [3]. Дополнительным преимуществом использования цифрового инструментария на корпоративном уровне, в том числе, при формировании и реализации стратегии развития хозяйствующего субъекта, является минимизация негативного влияния т.н. «человеческого фактора» (возможных ошибок при выполнении расчётных операций).

\section{Библиографический список}

1. Андреева Т.А. Интеграция принципов менеджмента качества и стратегического менеджмента / Андреева Т.А. // В сборнике: Актуальные проблемы управления: теория и практика. Материалы международной (заочной) научно-практической конференции. 2014. С. 3-7.

2. Анопченко Т.Ю. Этапы внедрения системы процессного управления для успешной трансформации существующих бизнес-коммуникаций / Анопченко Т.Ю., Даливалов М.3. // В сборнике: Современный менеджмент: теория и практика. материалы Всероссийской научно-практической конференции. 2017. С. 45-50.

3. Абраменко М.П. Цифровизация региональной экономики как фактор развития человеческого капитала (на материалах Ростовской области) / Абраменко М.П., Ревунов Р.В., Щербина М. М. // Региональные проблемы преобразования экономики. 2019. № 8(106). С. 144-150.

4. Недомолкина Я.Н. Положения стратегического менеджмента в обосновании концепции стратегического учёта / Недомолкина Я.Н. // Современная экономика: проблемы и решения. 2019. № 7(115). С. 79-94.

5. Anopchenko T. Y. Systems methodology and model tools for territorial sustainable management/Anopchenko T. Y., Gorbaneva O.I., Lazareva E. I., Murzin A.D., Ougolnitsky G. A.// Advances in Systems Science and Applications. 2018. T. 18. № 4. C. 136-150.

6. Anopchenko T. Y. Possibilities of the international cooperation and export of subjects of small and medium-sized business under the conditions of financial crisis / Anopchenko T. Y., Ostrovskiy V.I. // The Future of the Global Financial System: Downfall or Harmony. «Lecture Notes in Networks and Systems» Cham, Switzerland, 2019. C. 414-420.

7. Osadchaya N.A. Assessment of risks of investment and construction activities: Russian practice / Osadchaya N.A., Murzin A.D., Torgayan E.E. // Journal of Advanced Research in Law and Economics. 2017. T. 8. № 2. C. $529-544$. 